\title{
Molecular Pathology of Immune Checkpoint Inhibitor-Induced Myocarditis
}

\author{
Krystal A. Hughes ${ }^{1}$ and Gerald M. Higa ${ }^{1,2, *}$
}

${ }^{1}$ School of Pharmacy, Department of Clinical Pharmacy; ${ }^{2}$ School of Medicine, Section of
Hematology/Oncology, West Virginia University, Morgantown, WV 26506, USA

\begin{abstract}
The improvement in tumor outcomes associated with the use of immune checkpoint inhibitors (ICls) is supported by results of numerous clinical trials. Even though most publications reporting the clinical efficacy of these agents include a discussion of the biological mechanisms, narratives related to the complex nature of the adaptive immune response are frequently, though they should not be, mundane. It is also apparent that there tends to be a cursory, or even complete absence, of explanations related to the pathological mechanism(s) of the toxic reactions in the vast majority of papers that report adverse events associated with $\mathrm{ICl}$ therapy. Furthermore, the belief that cytotoxic $\mathrm{CD}^{+} \mathrm{T}$ cells mediate not only the antitumor, but also immune-related adverse, effects may be plausible, yet incorrect. This being the case, instead of providing only clinical details of a severe adverse event associated with combination ICI therapy in a patient with melanoma, the authors chose to scrutinize the repertoire and role of $T$ cells in the pathogenesis of myocarditis as an example of other $\mathrm{ICl}$-associated incidents of autoimmunity.
\end{abstract}

Keywords: Autoimmunity, CD4 ${ }^{+}$T cells, CTLA-4, CTLs, Immune checkpoint inhibitor, Myocarditis, PD-1.

\section{INTRODUCTION}

Diverse components of the innate and adaptive immune systems provide rigorous controls against foreign body encroachment. Even so, the protective effects associated with the immune response are not unilaterally favorable. For example, while pathogeninduced activation of the immune system promotes neutralization and removal of disease-causing agents, the enhanced reaction can also lead to excessive tissue damage. Fortunately, numerous mechanistic elements, some in the guise of cytokines such as interleukin-10 (IL-10) and transforming growth factorbeta (TGF- $\beta$ ), have the ability to ameliorate cellular injury by limiting the production of proinflammatory cytokines and chemokines [1]. In addition, IL-10 can also quell tissue reactivity directly by blocking the proliferation of $\mathrm{CD} 4^{+} \mathrm{T}$ cells and suppressing release of IL-2, interferon-gamma (IFN- $\mathrm{y}$ ), and tumor necrosis factor- $\alpha$ [2]. However, these same non-redundant counterregulatory mechanisms enable tumor cells to evade immune recognition and destruction [3-5]. Although inhibitory cytokines such as IL-10 and TGF- $\beta$ as well as cellular constituents of the innate (i.e., myeloid-derived suppressor cells) and adaptive (i.e., regulatory $\mathrm{T}$ and $\mathrm{B}$ cells) immune systems are among some of these opposing mechanisms, the immune checkpoint cytotoxic T lymphocyte antigen-4 (CTLA4)/B7 and programmed cell death protein-/ligand-1 (i.e., PD-1/PD-L1) pathways have become two of the primary targets of several therapeutic agents.

\footnotetext{
${ }^{*}$ Address correspondence to this author at the Professor of Clinical Pharmacy, Clinical Professor of Medicine, Schools of Pharmacy and Medicine, PO Box 9520, West Virginia University, Morgantown, WV 26506-9520, USA;

Tel: 304-293-1461; Fax: 304-293-7672; E-mail: ghiga@hsc.wvu.edu
}

Proof of principle clinical trials provided evidence that selective blockade of the CTLA-4 and PD-1 signaling pathways surreptitiously restores cellmediated immunity. Indeed, improved disease outcomes have been demonstrated not only for "immunologically-sensitive" tumors (i.e., melanoma and kidney cancer) but also for a broader range of solid carcinomas and a small number of hematologic malignancies. For example, blockade of CTLA-4 with the monoclonal antibody ipilimumab resulted in $\geq 2$-year overall survival in $20 \%$ of patients with previously treated metastatic melanoma [6]. Nivolumab, a novel PD-1 immune checkpoint inhibitor (ICl), has been shown to increase the median duration of overall survival in those with advanced melanoma from 17 months to 37 months [7]. Results of a clinical trial of a different PD-1 inhibitor demonstrated a significant improvement in overall survival among subjects with advanced non-small cell lung cancer treated with pembrolizumab compared to chemotherapy [8].

While the relatively broad applicability of these agents has been somewhat unanticipated, so has the development of a number of unique immune-related adverse events (ir-AEs) that appear to coincide with restoration of immune capability. A comprehensive overview of these autoimmune-like adverse events including the systems involved, incidence, manifestations, and management is well documented [9].

Although the development of ir-AEs is relatively common, most are low grade in severity. ICl-related toxicities involving the myocardium, which are typically more severe, are among the least frequently reported 
adverse reactions; the incidence of myocarditis has been reported to be approximately $0.5 \%$ [10]. And of the few published reports related to treatmentassociated cardiotoxicity, only one provided a brief summary of the potential molecular mechanism underlying the toxic event.

Despite its rarity, development of autoimmune myocarditis is associated with a poor prognosis and may be fatal despite early intervention with immunosuppressive therapies. This brief report describes the development and progression of fulminant myocarditis in a patient with melanoma following the first dose/first cycle of the combination of ipilimumab and nivolumab. The authors chose to diverge from focusing only on the clinical features of myocarditis as an example of other ir-AEs in general, which have been done numerous times before, instead opting to explore the complex biological mechanisms involved in these autoimmune events. Furthermore, the implication that cytotoxic $\mathrm{CD}^{+} \mathrm{T}$ cells mediate not only the antitumor effects but also the autoimmune reactions is probed as this belief, however rational, may be a specious misconception.

\section{CASE}

An 84-year-old Caucasian male presented to his primary care physician with a new, enlarging mass on the anterior right abdomen. A biopsy of the suspicious lesion was obtained in August 2020 and sent to pathology. Histopathologic review of the sampled tissue revealed a poorly differentiated, high-grade malignant neoplasm, possibly melanoma. Tumor slices were also sent to an outside facility for a second opinion. Immunohistochemistry was negative for a panel of proteins arguing against an epithelioid rhabdomyosarcoma. However, desmin-positive staining, a marker that can be seen in immunophenotypically aberrant metastasis, favored a diagnosis of an aggressive form of melanoma.

Positron emission tomography/computerized tomography (PET/CT) showed multiple hypermetabolic bilateral inguinal and right external iliac lymph nodes; a single hypermetabolic right inferior paratracheal node was also noted. MRI of the brain was negative. By surgical parameters, the tumor was at least stage IIIC $\left(T_{3 b}, N_{\geq 1}, M_{x}\right)$ [11]. Standard management involved performing a wide level excision with lymphadenectomy. Considering his age and comorbidities, operative risks and possibly micrometastases, the patient declined surgery. Instead, he agreed to a trial of combination systemic immunotherapy with ipilimumab and nivolumab for four cycles followed by nivolumab alone as long as treatment was tolerable and the disease did not progress. Treatment began in late September 2020.

Twenty-two days after the first dose of each drug, the patient presented to the emergency department with progressively worsening shortness of breath and significant weakness in all four extremities. Laboratory assessment showed B-type natriuretic peptide, 453 $\mathrm{pg} / \mathrm{mL}$; INR, 1.67; troponin, 48,741 ng/mL; ALT, 166 IU/L; and AST, $316 \mathrm{IU} / \mathrm{L}$. All other laboratory values were within normal limits. An electrocardiogram (ECG) showed bigeminy and interventricular conduction delay with no obvious ischemic changes. No acute processes were seen on CT of the brain, chest, abdomen, and pelvis. The patient was admitted to the hospital; cardiology was consulted for suspected non-ST elevated myocardial infarction.

Troponin, which was monitored every six hours, peaked at $84,528 \mathrm{ng} / \mathrm{mL}$ during the first 24 hours of admission. A bedside ECG performed was notable for global hypokinesis and left ventricular ejection fraction (LVEF) of $36 \%$. There was increased concern for new onset left-sided heart failure in the setting of acute coronary syndrome. In addition to aspirin, clopidogrel, furosemide and prophylactic heparin were started. Overnight, the patient developed severe, sharp, throbbing chest pain, several episodes of paroxysmal nocturnal dyspnea and hypoxia. And because of the additional concern for immunotherapy-mediated myocarditis, empiric methylprednisolone sodium succinate, $70 \mathrm{mg}$, intravenously, twice daily was initiated.

The following day the patient went for a heart catheterization which revealed two out of four nonpatent bypass grafts as well as a completely occluded vein graft for which a drug-elucidating stent was placed. After the procedure, the patient developed extreme chest pain. When his oxygen saturation decreased to $87 \%$, the 2 liters (L) by nasal cannula (NC) was replaced by a non-rebreather facemask. An additional dose of furosemide was given for new onset pulmonary edema. Respiratory personnel then placed him on continuous positive airway pressure with the intent to transition back to oxygen by nasal canula. The patient also received morphine and a nitroglycerine drip for symptomatic pain control. 
Consultants from both cardiology and oncology both agreed with a diagnosis of $\mathrm{ICl}$-induced myocarditis (grade 4 by ASCO criteria) [12] and polymyositis. Glucocorticoid therapy was modified to high-dose methylprednisolone, $1000 \mathrm{mg}$, daily with the addition of a second agent if no improvement was observed. A cardiac biopsy was also considered but not performed because of the invasive nature of the procedure and the subject's current clinical status. Subjectively, though, the patient stated that he was feeling much better and that the breathing and chest pain had improved significantly. The patient remained at full code status. Troponin levels trended down throughout the day from a maximum of $66,049 \mathrm{ng} / \mathrm{mL}$.

On day 3 of hospitalization, the patient had a cardiac magnetic resonance imaging (MRI) study. He declined to have a cardiac biopsy performed. Troponin decreased to $30,172 \mathrm{ng} / \mathrm{mL}$. However, he began to experience worsening shortness of breath with intermittent confusion. The patient also developed episodes of bradycardia (heart rate, $35-50$ beats per minute) and hypotension (blood pressure, 90/50 $\mathrm{mmHg}$ ). He was transferred to the cardiovascular intensive care unit. The etiology of the bradycardia was thought to be secondary to the inflammatory process and/or destruction of the conduction system. Diagnostic findings from the cardiac MRI were limited to a severely dilated left atrium, moderately dilated right atrium, and moderate mitral and tricuspid regurgitation. Subendocardial enhancement was also noted in the anteroseptal and apical segments with dyskinesis consistent with subendocardial infarction. An ECG indicated atrial fibrillation with left bundle branch block and junctional rhythm; LVEF was $<15 \%$. The patient's respiratory drive continued to decline the following day with close monitoring for possible intubation. Additional discussions included a therapeutic trial of intravenous immunoglobulin (IVIG).

On day 5 of admission, the patient complained of severe abdominal pain. His breathing became more labored, with use of his accessory muscles; heart rate fluctuated in and out of bigeminy. Oxygen supplementation was provided as needed. High-dose methylprednisolone was continued. Further workup with MRIs of the brain and heart could not be conducted due to pain. Troponin decreased to 21,349 $\mathrm{ng} / \mathrm{mL}$. The first (of five) dose of IVIG (400 mg/kg) was given. His weakness, shortness of breath, and difficulty swallowing continued through the following day. After the last dose of high-dose steroid, the glucocorticoid regimen was changed to $2 \mathrm{mg} / \mathrm{kg}$ twice daily.
On ensuing day 7 , the patient's breathing became more labored; respiratory placed him on intermittent bilevel positive airway pressure (BiPAP), the duration of which was adjusted based on comfort. While off BiPAP, the patient was placed on $3 \mathrm{~L} \mathrm{NC}$. After consult with supportive care, the patient changed his code status to do not intubate. His respiratory status did not change the following day. He became bradycardic throughout the day with heart rates as low as 30 beats per minute. An ECG revealed a high degree AV block. The risks and benefits of a permanent pacemaker was discussed with cardiology who recommended a biventricular pacemaker that could be inserted the following day. Cardiology also recommended starting dobutamine for inotropic support. Notably, after receiving the third dose of IVIG, the patient became hypotensive; dobutamine was replaced by epinephrine with some improvement in vital signs.

During the early morning of hospital day 9 , the patient developed severe hypoxemic respiratory failure, ventricular fibrillation and cardiac arrest. After successful cardiopulmonary resuscitation, he was placed back on BiPAP. However, the patient arrested again a few hours later at which point his family agreed that no further attempts at resuscitation be made.

\section{METHODS}

An online search was conducted for published reports of immunotherapy-associated myocarditis with a focus on the immunopathology of the adverse effect.

\section{RESULTS}

None of the published clinical trials using either or both agents contained information related to immune mechanisms of the toxicity. While a number of review or case reports have been published, only one paper attempted to elucidate the molecular basis of this adverse effect [13]. This prompted the authors to perform a rigorous review of autoimmunity in order to provide critical insight into this toxic reaction.

\section{DISCUSSION}

The combination of ipilimumab and nivolumab received FDA approval in October 2015 as frontline treatment for unresectable stage III or metastatic melanoma. Overall response rates with the doublet increased by $15 \%$ - $40 \%$ compared to either agent alone [14]. However, a significantly higher risk of allgrade ir-AEs was also an important part of the combination's clinical profile. The most frequently 
observed toxicities involved the integumentary (pruritis, rash), gastrointestinal (diarrhea, colitis, hepatitis), endocrine (thyroiditis, hypophysitis) and respiratory (pneumonitis) systems. Although some of these adverse effects can be serious, the fatality rate among those with endocrinopathies and colitis was $2 \%$ and $5 \%$, respectively [15]. In contrast, myocarditis had the highest fatality rate (39.7\% of the reported cases). The same meta-analysis reported that nearly $33 \%$ of all deaths with the ipilimumab/nivolumab regimen resulted from myocarditis, myositis, and neurologic events; median time from symptom onset to death was 32 days.

Under the canopy of the terms 'cardiovascular disease' are a number of diverse conditions which include cardiac fibrosis, cardiomyopathy, and heart failure. While the patient's long history of coronary artery disease and atrial fibrillation could contribute to all of these disorders, his age and comorbidities are less likely responsible for the new-onset myocarditis. Instead, blockade of the CTLA-4/B7 and PD-1/PD-L1 pathways appears to have triggered this iatrogenic cardiotoxic reaction. This apparent association provided the impetus to elucidate the molecular pathology of this hypersensitive phenomenon. While using the CTLA-4 pathway as the major source of information, the following discussion is an attempt to crystallize and reinforce the principles and particulars of $\mathrm{ICl}$-induced autoimmunity.

Even though inhibition of the two $\mathrm{T}$ cell inhibitory pathways transpired in FDA-approved agents less than 10 years ago, expression of CTLA-4 and PD- 1 was known at least two decades earlier. Findings from early studies indicated that CTLA-4 is a CD28-like receptor with homologous features such as chromosome locus and cytoplasmic tyrosine signaling motifs, as well as the co-stimulatory ligand-binding molecule, B-7 [16]. Still, some differences do exist. For example, the extracellular domain of CTLA- 4 is only $27 \%$ identical to the external domain of CD28. This lack of structural duplicity appears to be physiologically important. In contrast to monovalent binding of B7 to CD28, CTLA-4 exhibits divalent binding to two B7 molecules. The high-affinity binding characteristic of the latter results in the formation a more stable cell surface complex which also has physiologic importance [17,18]. Furthermore, the observation that antibodies directed against both receptors induced $T$ cell activation led to the conclusion that they were also functionally redundant [19]. Now it is known that only co-ligation of CTLA-4/B7 along with the $T$ cell receptor complex actually represses $T$ cell activation, proliferation, and functional activity [20]. It is also emphasized that CTLA-4 expression is not restricted to cytolytic T lymphocytes (CTLs; $\mathrm{CD}^{+} \mathrm{T}$ cells) as the receptor is also present on all subsets of helper $\mathrm{CD} 4^{+} \mathrm{T}$ cells (as well as $\mathrm{B}$, natural killer, and dendritic cells).

Notably, the cell-distribution pattern of PD-1 parallels that of CTLA-4; and like CTLA-4, messenger RNA or the PD-1 protein is usually detectable only after engagement of the $\mathrm{T}$ cell receptor and co-activation molecules or cytokine stimulation [21]. Not surprising is the finding that PD-1 and PD-L1 are also members of the CD28 and B7 family of receptors and ligands, respectively $[22,23]$. Their pronounced comparability, notwithstanding, receptor/ligand binding is invariably melded with cell function; yet the outcomes are not uniformly suppressive. The relevance of this assertion is discussed below.

Suppression of the cell-mediated anti-tumor effect should not conceal the equally important protective effect of CTLA-4 and PD-1 against autoimmune pathology. An understanding of both signaling pathways provides the framework to address the questionable peculiarity that activated CTLs are the primary mediators of the antitumor effect but not the autoimmune reactions. Although these sequelae appear to be discordant, target-specificities are biologically and immunologically reasonably accurate. Recall that during $T$ cell maturation, immature thymocytes undergo a judicious de-selection process through which $\sim 98 \%$ of $\mathrm{T}$ cells that react to self-major histocompatibility complex (MHC) molecules are eliminated to mitigate autoreactivity. This biological consequence, however, gives some credibility to the apparent discrepancy regarding the immune-mediated antitumor and adverse effects. For instance, while tumor cells are of "self" origin, generation of neoantigens during tumorigenesis stimulates binding of MHC class I molecules to "altered self" antigens [24]. These MHC:peptide complexes serve as the initial signal for the remaining $T$ cells to activate. After integrating two additional signals, the "altered antigen"specific $\mathrm{CD}^{+} \mathrm{T}$ cells undergo clonal expansion, which ultimately leads to tumor cell kill.

Conversely, positive selection should promote T cell tolerance and therefore, avoidance of autoimmune pathology. However, evidence for the less than complete absolution of CTLs in autoimmunity derives from the alleged role of $\mathrm{CD}^{+} \mathrm{T}$ cells in rheumatoid arthritis and Type 1 diabetes [25,26]. Moreover, the 
concern for cells that express MHC class I molecules as potential targets for cytotoxic damage comes with two important caveats. First, the presence of MHC class I, in the absence of co-stimulatory, molecules in the target cells would not generate a CTL response; and second, determination of the relevant self-antigen. Here autoimmune disorders have one thing in common, the native immunogen, in nearly all cases, is unknown.

Although the intent was not to marginalize the role of $\mathrm{CD}^{+} \mathrm{T}$ cells, a more compelling argument incriminating helper $\mathrm{CD}^{+} \mathrm{T}$ cells as the primary mediators of the ir-AEs is considered. Helper T (Th) cells consist of at least nine distinct subclasses, all progenies of one common progenitor [27]. Although specific subset destiny depends on a number of factors including type of antigen, cytokine milieu, and genetics [28], evidence suggests the involvement of heterogenous helper $\mathrm{T}$ cells in autoimmunity. Further characterization of these subcomponents strengthens this assertion. Th1 cells not only secrete proinflammatory cytokines such as IL-2 and IFN-y but also are potent macrophage activators. Indeed, the Th1 subset appears to be the primary "effector" of autoimmune diseases and tissue inflammation $[29,30]$. Th1 cells are also involved in cell-mediated immune reactions typified as delayed-type hypersensitivity [31]; and interestingly, all of the $\mathrm{ICl}$-associated autoimmune reactions are delayed phenomena, some occurring months after discontinuing drug therapy [32]. In contrast, Th2 and Th3 are helper "suppressor" subsets, in part, because they secrete anti-inflammatory cytokines including IL-4, IL-5, and TGF $\beta$. Furthermore, both Th2 and Th3 subsets have the ability to countermodulate the Th1-mediated inflammatory effect $[33,34]$.

Two additional subsets with vital immune regulatory capabilities are also part of the helper $\mathrm{CD}^{+} \mathrm{T}$ cell immune repertoire. One, labeled Type 1 regulatory (Tr1) cells release IL-10, a potent anti-inflammatory cytokine [35]. Most impressively, Tr1 cells have the ability to moderate established immune reactions mediated by Th1. As previously mentioned, $T_{\text {reg }}$ cells, a uniquely different subclone, appear to be critically important as these cells do not undergo clonal expansion in response to mitogenic stimulation, a feature characterized as anergy [36]. This finding, however, should not be construed that the cells are functionally inert. Phenotypically, $\mathrm{T}_{\text {reg }}$ cells are identified by surface expression of CD25 ( $\alpha$-chain of the IL-2 receptor) and Foxp3 (forkhead transcription factor). $T_{\text {reg }}$ cells also comprise a relatively small fraction of the pool of circulating $\mathrm{CD}^{+} \mathrm{T}$ cells. Nevertheless, animal models have demonstrated the importance of this subset, particularly when expression of the two surface markers are intact. In a murine model, investigators demonstrated that depletion of $\mathrm{CD}_{25}{ }^{+}$cells led to the development of several autoimmune diseases involving the thyroid, colon and pancreas [37]. Despite these findings, the expression of lineage-defining Foxp3 appeared to be functionally more important. To wit, studies in mice and humans have shown that loss or mutation of the Foxp3 gene not only perverts the growth and expansion of $T_{\text {reg }}$ cells but also promotes the development of lethal autoimmune syndromes [38,39]. In addition, aberrant expression of this transcription factor enabled deselection of $T_{\text {reg }}$ cells to other $T$ cell lineages capable of causing autoimmune pathology [40]. Another study even indicated that expression of Foxp3 results in restoration of the regulatory role of $C D 25^{-} \mathrm{T}_{\text {reg }}$ cells [41]. $T_{\text {reg }}$ cells are unusual in one other aspect in that CTLA-4 is constitutively expressed regardless of activation status [42]. This trait may have evolved as part of the critical role this $T$ helper subset has in order to enhance its protective effect. Indeed, an elegant study demonstrated that CTLA-4 in $\mathrm{T}_{\text {reg }}$ cells is required for stringent immune vigilance [43].

The data regarding $T$ cell immunology provide compelling evidence to support the assertion that CD4 ${ }^{+}$ $\mathrm{T}$ cells are the principal instigators of ir-AEs. Some of the most provocative evidence comes from studies in mice and humans. For instance, the CTLA-4 gene was cloned initially from $\mathrm{CD} 8^{+} \mathrm{T}$ cells in mice [44]. However, contrary to an earlier report, studies in humans revealed significantly higher expression of the bifunctional receptor in $\mathrm{CD} 4^{+}$compared to $\mathrm{CD}^{+} \mathrm{T}$ cells [45]. The significance of this finding may be linked to the receptor's repressive effect on T cells in general, and $\mathrm{CD}^{+}{ }^{+} \mathrm{T}$ cells specifically. Logically, knockout of CTLA-4 in $C D 8^{+} \mathrm{T}$ cells should, but unexpectedly does not, enable autoimmune-mediated cytotoxic effector $T$ cell activity. Instead, Gattinoni and colleagues demonstrated that autoimmune manifestations became apparent only by knocking down CTLA-4 on both cytotoxic and helper $T$ cell subsets [46]. The major inference is that $\mathrm{CD}^{+} \mathrm{T}$ cells are critical for the induction of autoimmune pathology though this notion does not completely exclude a role for $\mathrm{CD}^{+} \mathrm{T}$ cells.

Aside from autoimmunity, the presence of helper $T$ cells influences $\mathrm{CD}^{+} \mathrm{T}$ cell function in one other important dimension. In addition to pro-inflammatory IL12 , the importance of IL-2 or $\mathrm{T}$ cell growth factor in 
$\mathrm{CD}^{+} \mathrm{T}$ cell terminal differentiation is now well established [47]. However, well-defined in-vitro experiments with activated $\mathrm{CD}^{+}{ }^{+} \mathrm{T}$ cells demonstrated that cells cultured in medium containing high concentrations of IL-2 exhibited greater functionality and superior killing effect compared to cells grown in medium with low IL-2 concentrations. Notably, the principal source of IL-2 was activated $\mathrm{CD} 4^{+} \mathrm{T}$ cells [48]. These findings are particularly relevant because CTLA4 exerts a restrictive effect on $\mathrm{CD}^{+}{ }^{+} \mathrm{T}$ cell production of IL-2. Hence, receptor blockade is likely to have a significant influence on CTL-mediated antitumor effect $[49,50]$. As it relates to CTLA-4, these studies strongly suggest that receptor expression on $\mathrm{CD}^{+} \mathrm{T}$ cells is functionally more important than its presence on $\mathrm{CD} 8^{+}$ $T$ cells. In essence, the assertion expressed by others that ir-AEs result from "global activation of T cells" appears to be inaccurate. Moreover, anti-CTLA-4 antibody may not be a holistic activator of all helper $\mathrm{T}$ cell subsets. Indeed, if blockade of CTLA-4 resulted in activation of $\mathrm{T}_{\text {reg }}$ cells, then a more potent antiinflammatory, protective response would be expected. However, de-activation of constitutively expressed CTLA-4 on $\mathrm{T}_{\text {reg }}$ cells actually promoted the development of experimentally-induced Type 1 diabetes [43].

\section{CONCLUSION}

Despite the distinctive characterization of an apparent case of $\mathrm{ICl}$-related myocarditis, a conclusive diagnosis remained uncertain. Dissecting the complex biology of the $T$ cell classes involved in this adverse event proved to be equally challenging because of the duality of evidence. Even as expression of MHC class 1 molecules in nearly all cells supports the role of $\mathrm{CD}^{+}$ $T$ cells in inflammatory tissue injury, damaged tissue matter can be a source of peptides for presentation with class II molecules to $\mathrm{CD}^{+} \mathrm{T}$ cells. What is also contributing to the uncertainty is the continued evolution of the adaptive immune system. In reality, gaining uniform agreement with the proffered scientific explanations may be as difficult as achieving full acceptance of the theory of evolution. Nonetheless, credible particulars allied with the dynamic interactions of a cadre of $\mathrm{CD}^{+} \mathrm{T}$ helper cells provide appreciable support for their role in autoimmunity.

\section{CONFLICT OF INTEREST STATEMENT}

The authors have no financial relationship or other conflict of interest with industry, specifically related to any product referred to in, or could be inferred from, the contents of this paper.

\section{AUTHOR CONTRIBUTIONS}

$\mathrm{KAH}$ contributed to the concept, patient-related data acquisition, and manuscript review. GMH contributed to paper focus and concept, patient case review, and presided over writing and editing the manuscript. The authors approved the final draft of the manuscript and are accountable for all aspects of the work including its accuracy and integrity and all parts of their involvement in this proffered paper.

\section{REFERENCES}

[1] Moore KW, de Waal Malefyt R, Coffman RL, O'Garra A Interleukin-10 and the interleukin-10 receptor. Annu Rev Immunol 2001; 19(1): 683-765.

https://doi.org/10.1146/annurev.immunol.19.1.683

[2] Joss A, Akdis M, Faith A, Blaser KA, Akdis CA. IL-10 directly acts on $T$ cells by specifically altering the CD28 costimulation pathway. Eur J Immunol 2000; 30(6): 1683-90. https://doi.org/10.1002/1521-4141(200006)30:6<1683::AIDIMMU1683>3.0.CO;2-A

[3] Park M-J, Lee S-H, Kim E-K, Lee E-J, Baek J-A, Park S-H, et al. Interleukin-10 produced by myeloid-derived suppressor cells is critical for the induction of Tregs and attenuation of rheumat oid inflammation in mice. Sci Rep 2018; 8: 3753. https://doi.org/10.1038/s41598-018-21856-2

[4] Wan YY, Flavell RA. Regulatory T cells, transforming growth factor- $\beta$, and immune suppression. Proc Am Thorac Soc 2007; 4(3): 271-6.

https://doi.org/10.1513/pats.200701-020AW

[5] Rosser EC, Mauri C. Regulatory B cells: origin, phenotype, and function. Immunity $2015 ; 21 ; 42(4): 607-12$. https://doi.org/10.1016/j.immuni.2015.04.005

[6] McDermott D, Haanen J, Chen T-T, Lorigan P, O'Day S, for the MDX010-20 investigators. Efficacy and safety of ipilimumab in metastatic melanoma patients surviving more than 2 years following treatment in a phase III trial (MDX01020). Ann Oncol 2013; 24(10): 2694-8. https://doi.org/10.1093/annonc/mdt291

[7] Hodi, FS, Chiarion-Sileni V, Gonzalez R, Grob J-J, Rutkowski $\mathrm{P}$, Cowey $\mathrm{CL}$, et al. Nivolumab plus ipilimumab or nivolumab alone versus ipilimumab alone in advanced melanoma (Check Mate 067): 4-year outcomes of a multicentre, randomised, phase 3 trial. Lancet Oncol 2018; 19(11): 1480-92. https://doi.org/10.1016/S1470-2045(18)30700-9

[8] Mok TSK, Wu Y-L, Kudaba I, Kowalski DM, Cho BC, Turna $\mathrm{HZ}$, et al. Pembrolizumab versus chemotherapy for previously untreated, PD-L1-expressing, locally advanced or metastatic non-small-cell lung cancer (KEYNOTE-042): a randomized, open-label, controlled, phase 3 trial. Lancet 2019; 393(10183): 1819-30. https://doi.org/10.1016/S0140-6736(18)32409-7

[9] Rapoport BL, van Eeden R, Sibaud V, Epstein JB, Klastersky $\mathrm{J}$, Aapro $\mathrm{M}$, et al. Supportive care for patients undergoing immunotherapy. Supp Care Cancer 2017; 25(10): 3017-30. https://doi.org/10.1007/s00520-017-3802-9

[10] Hu YB, Zhang Q, Li HJ, Michot JM, Liu HB, Zhan P, et al. Evaluation of rare but severe immune related adverse effects in PD-1 and PD-L1 inhibitors in non-small cell lung cancer: a meta-analysis. Transl Lung Cancer Res 2017; 6(Suppl 1): S8-20.

https://doi.org/10.21037/tlcr.2017.12.10

[11] Amin MB, Edge S, Greene F, Byrd DR, Brookland RK, Washington MK, et al. AJCC Cancer Staging Manual. 8th ed. New York: Springer 2017.

https://doi.org/10.1007/978-3-319-40618-3 
[12] Brahmer JR, Lacchetti C, Schneider BJ, Atkins MB, Brassil $\mathrm{KJ}$, Caterino JM, et al. Management of immune-related adverse events in patients treated with immune checkpoint inhibitor therapy: American Society of Clinical Oncology Clinical Practice Guideline. J Clin Oncol 2018; 36(17): 171468.

https://doi.org/10.1200/JCO.2017.77.6385

[13] Palaskas N, Lopez-Mattei J, Durand JB, lliescu C, Deswal A. Immune checkpoint inhibitor myocarditis: pathophysiological characteristics, diagnosis, and treatment. J Am Heart Assoc 2020; 9(2): e0137579.

https://doi.org/10.1161/JAHA.119.013757

[14] Larkin J, Chiarion-Sileni V, Gonzalez R, Grob JJ, Cowey CL, Lao $C D$, et al. Combined nivolumab and ipilimumab or monotherapy in untreated melanoma. N Engl J Med 2015; 373(1): 23-34. https://doi.org/10.1056/NEJMoa1504030

[15] Wang DY, Salem JE, Cohen JV. Fatal toxic effects associated with immune checkpoint inhibitors: a systematic review and meta-analysis. JAMA Oncol 2018; 4(12): 1721-8. https://doi.org/10.1001/jamaoncol.2018.3923

[16] Harper K, Balzano C, Rouvier E, Mattéi MG, Luciani MF, Golstein P. CTLA-4 and CD28 activated lymphocyte molecules are closely related in both mouse and human as to sequence, message expression, gene structure, and chromosomal location. J Immunol 1991 Aug 1; 147(3): 103744.

[17] Collins AV, Brodie DW, Gilbert RJ, laboni A, Manso-Sancho $\mathrm{R}$, Walse $\mathrm{B}$, et al. The interaction properties of costimulatory molecules revisited. Immunity 2002; 17(2): 201-10. https://doi.org/10.1016/S1074-7613(02)00362-X

[18] Lindsten T, Lee KP, Harris ES, Petryniak B, Craighead N, Reynolds PJ, et al. Characterization of CTLA-4 structure and expression on human T cells. J Immunol 1993; 151(7): 348999.

[19] Linsley PS, Greene JL, Tan P, Bradshaw J, Ledbetter JA, Anasetti $\mathrm{C}$, et al. Coexpression and functional cooperation of CTLA-4 and CD28 on activated T lymphocytes. J Exp Med 1992; 176(6): 1595-1604.

https://doi.org/10.1084/jem.176.6.1595

[20] Walunas TL, Lenschow DJ, Bakker CY, Linsley PS, Freeman GJ, Green JM, et al. CTLA-4 can function as a negative regulator of T cell activation. Immunity 1994; 1(5): 405-13. https://doi.org/10.1016/1074-7613(94)90071-X

[21] Kinter AL, Godbout EJ, McNally JP, Sereti I, Roby GA, O'Shea MA, et al. The common gamma-chain cytokines IL-2, IL-7, IL-15, and IL-21 induce the expression of programmed death-1 and its ligands. J Immunol 2008; 181(10): 6738-46. https://doi.org/10.4049/jimmunol.181.10.6738

[22] Freeman GJ, Long AJ, Iwai Y, Bourque K, Chernova T, Nishimura $\mathrm{H}$, et al. Engagement of the PD-1 immunoinhibitory receptor by a novel B7 family member leads to negative regulation of lymphocyte activation. J Exp Med 2000; 192(7): 1027-34. https://doi.org/10.1084/jem.192.7.1027

[23] Lin DY, Tanaka Y, Iwasaki M, Gittis AG, Su HP, Mikami B, et al. The PD-1/PD-L1 complex resembles the antigen-binding Fv domains of antibodies and $T$ cell receptors. Proc Natl Acad Sci U S A 2008; 105(8): 3011-6. https://doi.org/10.1073/pnas.0712278105

[24] Zinkernagel RM, Doherty PC. Immunological surveillance against altered self-components by sensitised $\mathrm{T}$ lymphocytes in lymphocytic choriomeningitis. Nature 1974; 251(5475): 547-8.

https://doi.org/10.1038/251547a0

[25] Berner B, Akca D, Jung T, Muller GA, Reuss-Borst MA. Analysis of Th1 and Th2 cytokines expressing CD4+ and $\mathrm{CD} 8+\mathrm{T}$ cells in rheumatoid arthritis by flow cytometry. $\mathrm{J}$ Rheumatol 2000; 27(5): 1128-35.
[26] Wong F, Karttunen J, Dumont C, Wen L, Visintin I, Pilip I, et al. Identification of an MHC class I-restricted autoantigen in type 1 diabetes by screening an organ-specific cDNA library. Nat Med 1999; 5(9): 1026-31.

https://doi.org/10.1038/12465

[27] Rocken M, Saurat JH, Hauser C: A common precursor for CD4+ T cells producing IL-2 or IL-4. J Immunol 1992; 148(4): 1031-6.

[28] Raphael I, Nalawade S, Eagar TN, Forsthuber TG. T cell subsets and their signature cytokines in autoimmune and inflammatory diseases. Cytokine 2015; 74(1): 5-17. https://doi.org/10.1016/j.cyto.2014.09.011

[29] Van Boxel JA, Paget SA. Predominantly T-cell infiltrate in rheumatoid synovial membranes. N Engl J Med 1975; 293(11): 517-20. https://doi.org/10.1056/NEJM197509112931101

[30] Banerjee S, Webber C, Poole AR: The induction of arthritis in mice by the cartilage proteoglycan aggrecan: roles of CD4+ and CD8+ T cells. Cell Immunol 1992; 144(2): 347-57. https://doi.org/10.1016/0008-8749(92)90250-S

[31] Abbas AK, Murphy KM, Sher A. Functional diversity of helper T lymphocytes. Nature 1996; 383(6603): 787-93. https://doi.org/10.1038/383787a0

[32] Hassel JC, Heinzerling L, Aberle J, Bähr O, Eigentler TK Grimm MO, et al. Combined immune checkpoint blockade (anti-PD-1/anti-CTLA-4): Evaluation and management of adverse drug reactions. Cancer Treat Rev 2017; 57: 36-49. https://doi.org/10.1016/j.ctrv.2017.05.003

[33] Alegre ML, Shiels H, Thompson CB, Gajewski TF. Expression and function of CTLA-4 in Th1 and Th2 cells. J Immunol 1998; 161(7): 3347-56.

[34] Groux H, O'Garra A, Bigler M, Rouleau M, Antonenko S, de Vries, et al. A CD4+ T-cell subset inhibits antigen-specific Tcell responses and prevents colitis. Nature 1997; 389(6652): 737-42. https://doi.org/10.1038/39614

[35] Foussat A, Cottrez F, Brun V, Fournier N, Breittmayer J-P, Groux $\mathrm{H}$. Comparative study between $\mathrm{T}$ regulatory type 1 and $\mathrm{CD} 4^{+} \mathrm{CD} 25^{+} \mathrm{T}$ cells in the control of inflammation. $\mathrm{J}$ Immunol 2003; 171(10): 5018-26. https://doi.org/10.4049/jimmunol.171.10.5018

[36] Kalekar LA, Mueller DL. Relationship between CD4 regulatory T cells and anergy in vivo. J Immunol 2017; 198(7): 2527-33. https://doi.org/10.4049/jimmunol.1602031

[37] Sakaguchi S, Sakaguchi N, Asano M, Itoh M, Toda M. Immunologic self-tolerance maintained by activated $T$ cells expressing IL-2 receptor alpha-chains (CD25). Breakdown of a single mechanism of self-tolerance causes various autoimmune diseases. J Immunol 1995; 155(3): 1151-64.

[38] Fontenot, J. D., Gavin MA, Rudensky AY. Foxp3 programs the development and function of CD4+CD25+ regulatory $T$ cells. Nat Immunol 2003; 4(4): 330-6.

https://doi.org/10.1038/ni904

[39] Bennett CL, Christie J, Ramsdell F, Brunkow ME, Ferguson $\mathrm{PJ}$, Whitesell $\mathrm{L}$, et al. The immune dysregulation, polyendocrinopathy, enteropathy, X-linked syndrome (IPEX) is caused by mutations of FOXP3. Nat Genet 2001; 27(1): 20-1. https://doi.org/10.1038/83713

[40] Zhou X, Bailey-Bucktrout SL, Jeker LT, Penaranda C Martinez-Llordella $\mathrm{M}$, Ashby $\mathrm{M}$, et al. Instability of the transcription factor Foxp3 leads to the generation of pathogenic memory T cells in vivo. Nat Immunol 2009; 10(9): 1000-7.

https://doi.org/10.1038/ni.1774

[41] Hori S, Takahashi T, Sakaguchi S. Control of autoimmunity by naturally arising regulatory CD4+ T cells. Adv Immunol 2003; 81: 331-71. https://doi.org/10.1016/S0065-2776(03)81008-8 
[42] Takahashi T, Tagami T, Yamazaki S, Uede T, Shimizu J, Sakaguchi N, et al. Immunologic self-tolerance maintained by CD25+CD4+ regulatory $T$ cells constitutively expressing cytotoxic $T$ lymphocyte-associated antigen 4. J Exp Med 2000; 192(2): 303-10. https://doi.org/10.1084/jem.192.2.303

[43] Schmidt EM, Wang CJ, Ryan GA, Clough LE Qureshi OS, Goodall $\mathrm{M}$, et al. Ctla-4 controls regulatory $\mathrm{T}$ cell peripheral homeostasis and is required for suppression of pancreatic islet autoimmunity. J Immunol 2009; 182(1): 274-82. https://doi.org/10.4049/jimmunol.182.1.274

[44] Brunet JF, Denizot F, Luciani MF, Roux-Dosseto M, Suzan $\mathrm{M}$, Mattei MG, et al. A new member of the immunoglobulin superfamily--CTLA-4. Nature 1987; 328(6127): 267-70. https://doi.org/10.1038/328267a0

[45] Chan DV, Gibson HM, Aufiero BM, Wilson AJ, Hafner MS, Mi $\mathrm{Q}-\mathrm{S}$, et al. Differential CTLA-4 expression in human CD4+ versus CD8+ T cells is associated with increased NFAT1 and inhibition of CD4+ proliferation. Genes Immun 2014; 15(1): 25-32.

https://doi.org/10.1038/gene.2013.57
[46] Gattinoni L, Ranganathan A, Surman DR, Palmer DC, Antony PA, Theoret MR, et al. CTLA-4 dysregulation of self/tumor-reactive CD8+ T-cell function is CD4+ T-cell dependent. Blood 2006; 108(12): 3818-23. https://doi.org/10.1182/blood-2006-07-034066

[47] Hinrichs CS, Spolski R, Paulos CM, Gattinoni L, Kerstann $\mathrm{KW}$, Palmer DC, et al. IL-2 and IL-21 confer opposing differentiation programs to $\mathrm{CD}^{+} \mathrm{T}$ cells for adoptive immunotherapy. Blood 2008; 111(11): 5326-33. https://doi.org/10.1182/blood-2007-09-113050

[48] Malek TR, Castro I. Interleukin-2 receptor signaling: At the interface between tolerance and immunity. Immunity 2010; 33(2): 153-65.

https://doi.org/10.1016/j.immuni.2010.08.004

[49] Krummel MF, Allison JP. CTLA-4 engagement inhibits IL-2 accumulation and cell cycle progression upon activation of resting T cells. J Exp Med 1996; 183(6): 2533-40. https://doi.org/10.1084/jem.183.6.2533

[50] Williams MA, Tyznik AJ, Bevan MJ. Interleukin-2 signals during priming are required for secondary expansion of CD8+ memory T cells. Nature 2006; 441(7095): 890-3. https://doi.org/10.1038/nature04790

(C) 2020 Hughes and Higa; Licensee Neoplasia Research.

This is an open access article licensed under the terms of the Creative Commons Attribution Non-Commercial License (http://creativecommons.org/licenses/by-nc/3.0/) which permits unrestricted, non-commercial use, distribution and reproduction in any medium, provided the work is properly cited. 